DOI: https://doi.org/10.33330/jurteksi.v6i2.406

Available online at http://jurnal.stmikroyal.ac.id/index.php/jurteksi

\title{
PENERAPAN MODEL WATERFALL DALAM ANALISIS PERANCANGAN SISTEM INFORMASI INVENTARISASI BERBASIS WEB
}

\author{
Oky Irnawati ${ }^{1 *}$, Ida Darwati ${ }^{2}$ \\ ${ }^{1}$ Program Studi Teknik Elektro, Universitas Bina Sarana Informatika \\ ${ }^{2}$ Program Studi Sistem Informasi, Universitas Bina Sarana Informatika \\ email: oky.okt@bsi.ac.id
}

\begin{abstract}
The author reflects on one private company engaged in the field of communication that is still carrying out the process of inventory of conventional goods. In this study the authors conducted a web-based inventory information system design analysis, the authors used the Waterfall, the Java programming language the author chose in designing this inventory application. This web-based inventory application is to support the process of monitoring goods so that they can be better controlled so that they can become a reference as a decision-maker quickly.
\end{abstract}

Keywords: Inventory; Waterfall Model; Web Based

\begin{abstract}
Abstrak: Penulis melakukan pengamatan terhadap salah satu perusahaan swasta yang bergerak dalam bidang komunikasi yang masih melakukan proses inventaris barang secara konvensional. Pada penelitian ini penulis melakukan analisis perancangan sistem informasi inventarisasi berbasis web, penulis menggunakan model Waterfall, bahasa pemrograman Java dipilih penulis dalam merancang aplikasi inventarisasi ini. Aplikasi inventarisasi berbasis web ini untuk mendukung proses monitoring barang agar dapat terkontrol dengan lebih baik lagi sehingga dapat menjadi acuan sebagai pengambil keputusan dengan cepat.
\end{abstract}

Kata kunci: Berbasis Web; Inventaris; Model Waterfall

\section{PENDAHULUAN}

Pengelolaan inventaris barang yang tidak terkontrol dengan baik dapat menyebabkan ketidakakuratan informasi mengenai ketersediaan dan kondisi inventaris barang pada suatu perusahaan [1]-[3], karena dari informasi inilah yang menentukan keputusan apa yang harus diambil selanjutnya. Informasi adalah pesan (ucapan atau ekspresi) atau kumpulan pesan yang terdiri dari order sekuens dari simbol, atau makna yang dapat ditafsirkan dari pesan atau kumpulan pesan [4]-[6]

Pada penelitian ini diusulkan
perancangan sistem informasi
inventarisasi berbasis web untuk
memudahkan pengontrolan inventaris
barang sehingga prosesnya menjadi
lebih mudah dan terdata dengan baik,


JURTEKSI (Jurnal Teknologi dan Sistem Informasi)

Vol. 6 No. 2, April 2020, hlm. 109 - 116

DOI: https://doi.org/10.33330/jurteksi.v6i2.406

Available online at http://jurnal.stmikroyal.ac.id/index.php/jurteksi

serta proses yang lebih cepat. Penggunaan teknologi informasi di perusahaan dan dunia bisnis sangat membantu manusia dalam menyelesaikan pekerjaan secara cepat dan tepat [7]-[10]

\section{METODE}

Penelitian ini menggunakan model Waterfall. Model air terjun menyediakan pendekatan alur hidup perangkat lunak secara sekuensial atau terurut dimulai dari analisis, desain, pengkodean, pengujian, dan tahap pendukung (support) [11], [12].

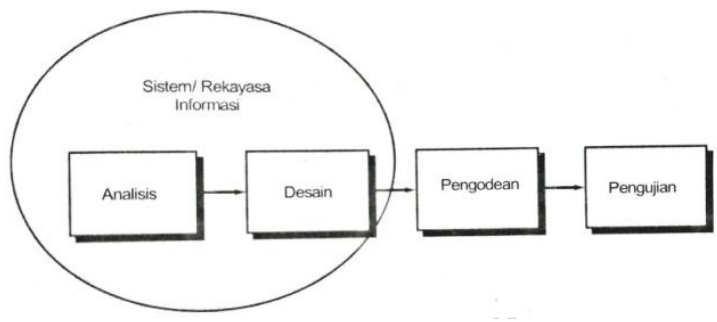

Gambar 1. Ilustrasi model Waterfall[11]

Penerapan model Waterfall menurut Sukamto dan Shalahuddin [11] pada penelitian ini yaitu sebagai berikut:

1. Analisis Kebutuhan Perangkat Lunak

Informasi yang didapatkan dari hasil penelitian diketahui bahwa sistem inventaris barang yang diterapkan masih menggunakan sistem konvensional, sehingga penulis merancang sebuah sistem informasi untuk lebih memudahkan perusahaan dalam mengelola inventaris barang.

2. Desain

Pada tahap ini penulis membuat rancangan database yang berisi tabel-tabel yang saling berelasi untuk menyimpan data inventaris.
3. Pembuatan Kode Program

Pada perancangan sistem ini, penulis menggunakan bahasa pemrograman Java.

4. Pengujian

Pengujian dilakukan untuk mengetahui bahwa perancangan aplikasi sudah sesuai dengan kebutuhan perusahaan.

5. Pendukung (Support) atau Pemeliharaan (Maintenance)

Software dan hardware yang tepat dibutuhkan untuk membangun dan menjalankan peracangan sistem informasi ini, yang nantinya harus sering dilakukan pemeliharaan guna menjaga agar perancangan sistem ini selalu sesuai dengan fungsinya.

\section{HASIL DAN PEMBAHASAN}

Penelitian terdahulu [13] Dedy menyatakan bahwa berdasarkan pencatatan secara manual tersebut mengakibatkan sulitnya mendeteksi peralatan-peralatan laboratorium yang rusak, hilang, berpindah dari satu laboratorium ke laboratorium yang lain dan bahan habis yang digunakan dalam proses belajar mengajar, sehingga pada saat akan dilakukan audit internal maupun eksternal, teknisi, kasublab, dan kalab cenderung kesulitan menginventarisasi peralatan yang ada, sehingga inventaris barang yang dicantumkan hanya peralatan yang ada pada saat ini saja dan bahan habis pakai ditulis secara tidak transparan [14].

a. Analisis Kebutuhan Perangkat Lunak

Proses inventaris barang yang dapat terjadi setelah dilakukan 
JURTEKSI (Jurnal Teknologi dan Sistem Informasi)

Vol. 6 No. 2, April 2020, hlm. 109 - 116

DOI: https://doi.org/10.33330/jurteksi.v6i2.406

Available online at http://jurnal.stmikroyal.ac.id/index.php/jurteksi

perubahan sistem menjadi terkomputerisasi adalah sebagai berikut:

\section{Form Data Barang}

Form data barang digunakan untuk mendata inventaris barang yang telah ada. Mendata barang yang tersedia, rusak maupun barang yang baru masuk. Pada form data barang juga dapat dilihat tanggal barang tersebut masuk maupun keluar sehingga memudahkan proses inventarisasi. Fasilitas yang disediakan pada form barang yaitu tambah barang baru, tambah stok barang, tambah barang rusak, hapus data barang dan lihat data barang.

2. Form Permintaan Barang

Form permintaan barang digunakan untuk memproses permintaan barang sekaligus merekam terjadinya barang keluar yang merubah jumlah data barang tersedia. Adanya form ini memudahkan proses permintaan barang serta memudahkan inventaris barang. Fitur yang disediakan pada form permintaan barang yaitu edit permintaan barang, hapus permintaan barang dan lihat data permintaan barang.

3. Cetak Bukti Penyerahaan Barang Pencetakan bukti barang keluar adalah hasil dari form penyerahan barang sebagai bukti cetak yang akan diserahkan bersamaan dengan fisik barang. Selain dapat mencetak form penyerahan barang juga dapat melihat history penyerahan barang yang telah ada sebelumnya.
A. Desain

1. Desain Sistem

Aplikasi dimodelkan dengan menggunakan Unified Modelling Language (UML) sehingga terlihat jelas seperti apa sistematika dan operasi penggunaan dari aplikasi yang dirancang [15].

a) Use Case Diagram

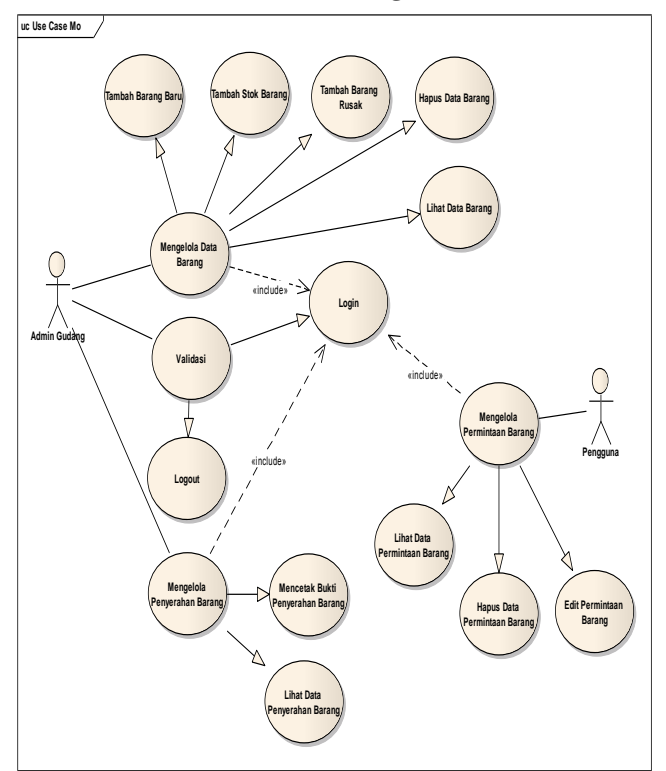

Gambar 2. Use Case Diagram Menu Utama

b) Activity Diagram

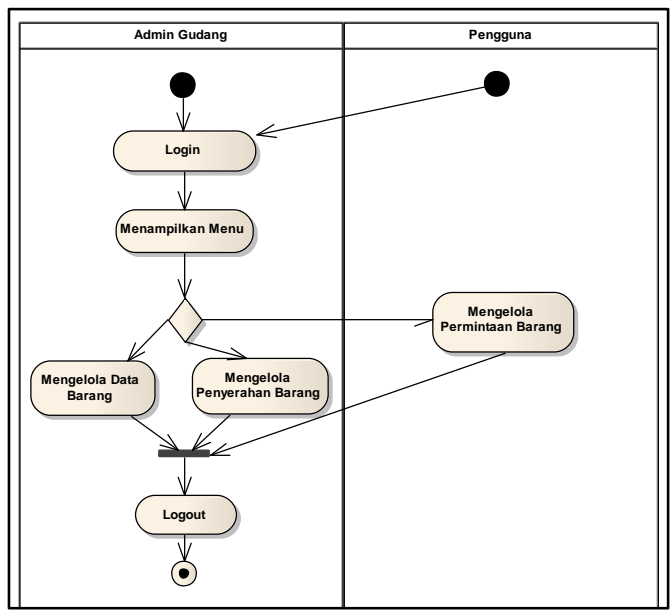

Gambar 3. Activity Diagram Menu Utama 
JURTEKSI (Jurnal Teknologi dan Sistem Informasi)

Vol. 6 No. 2, April 2020, hlm. 109 - 116

DOI: https://doi.org/10.33330/jurteksi.v6i2.406

Available online at http://jurnal.stmikroyal.ac.id/index.php/jurteksi

2. Desain Pembuatan Database

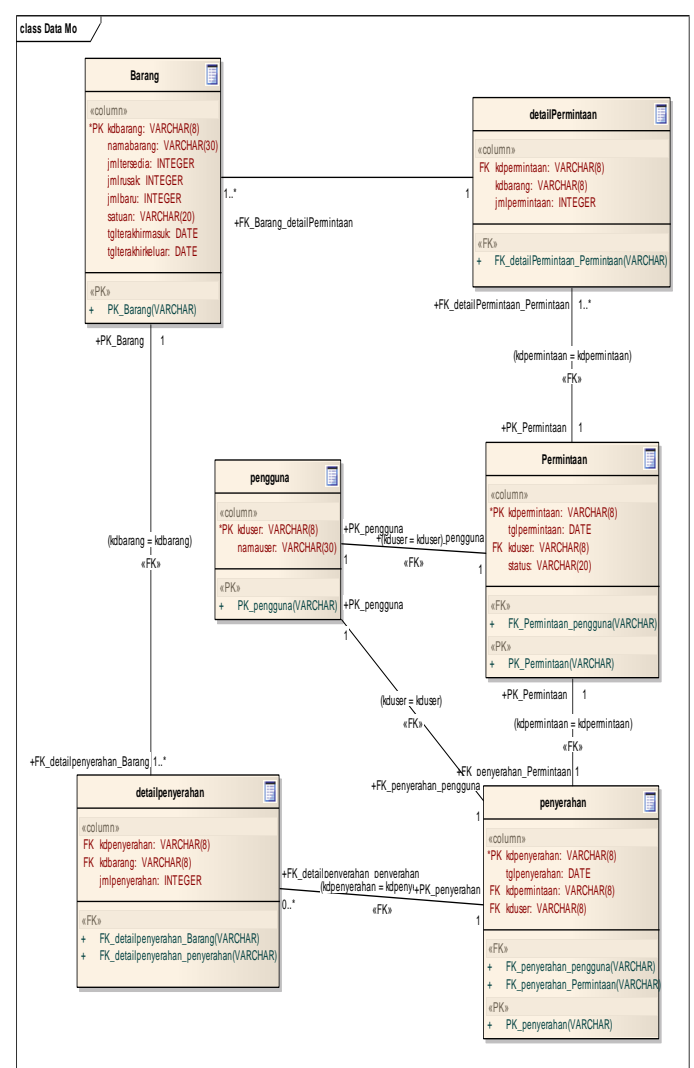

Gambar 4. Data Model

3. Desain User Interface

a) Desain Tampilan Input Data Barang

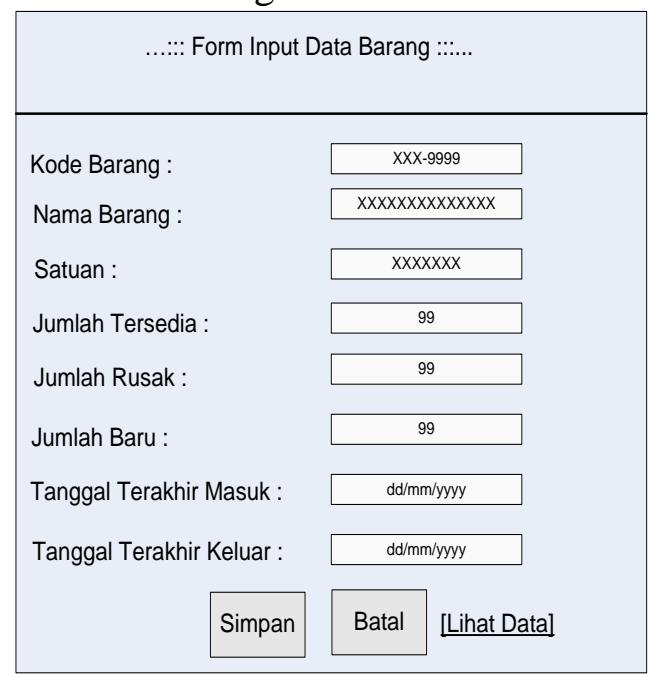

Gambar 5. Desain Tampilan Input Data Barang
ISSN 2407-1811 (Print)

ISSN 2550-0201 (Online) 
JURTEKSI (Jurnal Teknologi dan Sistem Informasi)

Vol. 6 No. 2, April 2020, hlm. 109 - 116

DOI: https://doi.org/10.33330/jurteksi.v6i2.406

Available online at http://jurnal.stmikroyal.ac.id/index.php/jurteksi

\begin{tabular}{|c|c|c|c|c|}
\hline \multicolumn{5}{|c|}{...::: Form Input Data Permintaan Barang ::..... } \\
\hline Kode Permintaan : $\square$ & Tanggal Permintaan : [ & $\mathrm{dd} / \mathrm{mm} / \mathrm{yyyy}$ & Kode User : & XXX-9999 \\
\hline Nama Barang & \multicolumn{2}{|l|}{ Jumlah Tersedia } & \multicolumn{2}{|c|}{ Jumlah Permintaan } \\
\hline$x x x x x x x x x x x x x x$ & 99 & & \multicolumn{2}{|r|}{99} \\
\hline 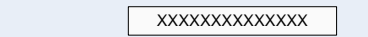 & 99 & & \multicolumn{2}{|r|}{99} \\
\hline$x x x x x x x x x x x x x x$ & 99 & & \multicolumn{2}{|r|}{99} \\
\hline & & Simpan & Tambah Baris & [Lihat Data] \\
\hline
\end{tabular}

Gambar 7. Desain Tampilan Permintaan Barang Inventaris

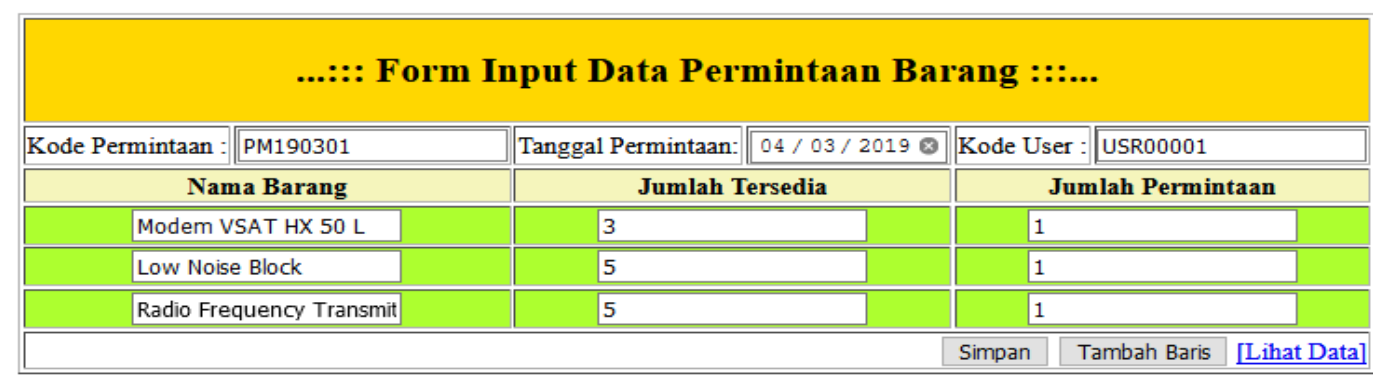

Gambar 8. Tampilan Form Permintaan Barang Inventaris

Tabel 1. Pengujian Form Input Barang

\begin{tabular}{|c|c|c|c|c|c|}
\hline No & $\begin{array}{l}\text { Sekenario } \\
\text { Pengujian }\end{array}$ & Test Case & $\begin{array}{c}\text { Hasil yang } \\
\text { Diharapkan }\end{array}$ & $\begin{array}{c}\text { Hasil } \\
\text { Pengujian }\end{array}$ & Kesimpulan \\
\hline 1 & $\begin{array}{l}\text { Menginput } \\
\text { data barang } \\
\text { dengan } \\
\text { mengosongkan } \\
\text { salah satu field }\end{array}$ & $\begin{array}{l}\text { Salah satu } \\
\text { field kosong }\end{array}$ & $\begin{array}{l}\text { Sistem akan } \\
\text { menolak } \\
\text { akses "Data } \\
\text { tidak boleh } \\
\text { kosong" }\end{array}$ & $\begin{array}{l}\text { Sesuai } \\
\text { Harapan }\end{array}$ & Valid \\
\hline 2 & $\begin{array}{l}\text { Menginput } \\
\text { data barang } \\
\text { dengan kode } \\
\text { barang yang } \\
\text { sudah ada }\end{array}$ & $\begin{array}{l}\text { Kode barang: } \\
\text { diisi sama } \\
\text { dengan kode } \\
\text { barang yang } \\
\text { ada dalam } \\
\text { table barang }\end{array}$ & $\begin{array}{l}\text { Sistem akan } \\
\text { menampilkan } \\
\text { nama barang, } \\
\text { satuan dan } \\
\text { jumlah } \\
\text { tersedia }\end{array}$ & $\begin{array}{l}\text { Sesuai } \\
\text { Harapan }\end{array}$ & Valid \\
\hline 3 & $\begin{array}{l}\text { Menginput } \\
\text { jumlah } \\
\text { tersedia, } \\
\text { jumlah rusak } \\
\text { dan jumlah } \\
\text { baru dengan } \\
\text { karakter selain } \\
\text { angka }\end{array}$ & $\begin{array}{l}\text { Jumlah } \\
\text { Tersedia: } x \text {, } \\
\text { jumlah rusak: } \\
\text { y, jumlah } \\
\text { baru: } \mathrm{z}\end{array}$ & $\begin{array}{l}\text { Sistem akan } \\
\text { menolak } \\
\text { dengan field } \\
\text { tidak bisa } \\
\text { diketik }\end{array}$ & $\begin{array}{l}\text { Sesuai } \\
\text { Harapan }\end{array}$ & Valid \\
\hline
\end{tabular}


JURTEKSI (Jurnal Teknologi dan Sistem Informasi)

Vol. 6 No. 2, April 2020, hlm. 109 - 116

DOI: https://doi.org/10.33330/jurteksi.v6i2.406

Available online at http://jurnal.stmikroyal.ac.id/index.php/jurteksi

Tabel 2. Pengujian Form Permintaan Barang Inventaris

\begin{tabular}{|c|c|c|c|c|c|}
\hline No & $\begin{array}{l}\text { Sekenario } \\
\text { Pengujian }\end{array}$ & Test Case & $\begin{array}{c}\text { Hasil yang } \\
\text { Diharapkan }\end{array}$ & $\begin{array}{c}\text { Hasil } \\
\text { Penguji } \\
\text { an } \\
\end{array}$ & Kesimpulan \\
\hline 1 & $\begin{array}{l}\text { Menginput data } \\
\text { permintaan } \\
\text { barang dengan } \\
\text { mengosongkan } \\
\text { salah satu field }\end{array}$ & $\begin{array}{l}\text { Salah satu field } \\
\text { kosong }\end{array}$ & $\begin{array}{l}\text { Sistem akan } \\
\text { menolak } \\
\text { akses "Data } \\
\text { tidak boleh } \\
\text { kosong", }\end{array}$ & $\begin{array}{l}\text { Sesuai } \\
\text { Harapan }\end{array}$ & Valid \\
\hline 2 & $\begin{array}{l}\text { Menginput nama } \\
\text { barang yang } \\
\text { belum ada di } \\
\text { table barang }\end{array}$ & $\begin{array}{ll}\text { Nama } & \text { Barang: } \\
\text { diisi } & \text { dengan } \\
\text { XYZ } & \end{array}$ & $\begin{array}{l}\text { Muncul } \\
\text { pesan } \\
\text { "Barang tidak } \\
\text { terdaftar" }\end{array}$ & $\begin{array}{l}\text { Sesuai } \\
\text { Harapan }\end{array}$ & Valid \\
\hline 3 & $\begin{array}{l}\text { Menginput field } \\
\text { yang seharusnya } \\
\text { tampil otomatis }\end{array}$ & $\begin{array}{l}\text { Kode } \\
\text { permintaan: } \\
\text { diketik manual } \\
\text { Tanggal } \\
\text { permintaan: } \\
\text { diketik manual } \\
\text { Kode user: } \\
\text { diketik manual } \\
\text { Jumlah } \\
\text { tersedia: diketik } \\
\text { manual }\end{array}$ & $\begin{array}{l}\text { Sistem akan } \\
\text { menolak } \\
\text { penginputan }\end{array}$ & $\begin{array}{l}\text { Sesuai } \\
\text { Harapan }\end{array}$ & Valid \\
\hline 4 & $\begin{array}{l}\text { Menginput nama } \\
\text { barang yang } \\
\text { sudah ada di } \\
\text { table barang }\end{array}$ & $\begin{array}{l}\text { Nama barang: } \\
\text { Modem VSAT } \\
\text { HX 50 L }\end{array}$ & $\begin{array}{l}\text { Sistem akan } \\
\text { mencari data } \\
\text { di table } \\
\text { barang dan } \\
\text { menampilkan } \\
\text { hasi } \\
\text { pencarian }\end{array}$ & $\begin{array}{l}\text { Sesuai } \\
\text { Harapan }\end{array}$ & Valid \\
\hline 5 & $\begin{array}{l}\text { Menginput } \\
\text { jumlah } \\
\text { permintaan lebih } \\
\text { besar dari jumlah } \\
\text { tersedia }\end{array}$ & $\begin{array}{l}\text { Jumlah } \\
\text { tersedia: } 3 \\
\text { Jumlah } \\
\text { permintaan: } 4\end{array}$ & $\begin{array}{l}\text { Muncul } \\
\text { pesan } \\
\text { "Jumlah } \\
\text { permintaan } \\
\text { barang lebih } \\
\text { besar dari } \\
\text { jumlah } \\
\text { barang yang } \\
\text { tersedia }\end{array}$ & $\begin{array}{l}\text { Sesuai } \\
\text { Harapan }\end{array}$ & Valid \\
\hline
\end{tabular}

ISSN 2407-1811 (Print)

ISSN 2550-0201 (Online) 
JURTEKSI (Jurnal Teknologi dan Sistem Informasi)

Vol. 6 No. 2, April 2020, hlm. 109 - 116

DOI: https://doi.org/10.33330/jurteksi.v6i2.406

Available online at http://jurnal.stmikroyal.ac.id/index.php/jurteksi

\section{SIMPULAN}

Berdasarkan hasil dan pembahasan dari penelitian ini, dapat disimpulkan bahwa dengan sistem informasi inventarisasi berbasis web dapat memudahkan dalam mengontrol inventaris barang, sistem informasi inventarisasi mempercepat proses pengolahan data inventaris barang dengan cepat dan tepat.

\section{DAFTAR PUSTAKA}

[1] N. Huda and R. Amalia, "Implementasi Sistem Informasi Inventaris barang Pada PT. PLN (persero) Palembang," J. Sisfokom, vol. 9, no. 1, pp. 13-19, 2020.

[2] M. A. Wardana, "Sistem Informasi Inventory Barang Kantor PT. POS (PERSERO) Kabupaten Soppeng," J. Ilm. Sist. Inf. dan Tek. Inform., vol. 1, no. 2, pp. 42-50, 2018.

[3] A. Hafidz, "Pengembangan Industri Shuttle Cock Untuk Meningkatkan Daya Saing Pasar di Kabupaten Nganjuk," in Semnas PPM 2018, 2018, pp. 613-622.

[4] Irianto, "Perancangan Sistem Informasi Pembuatan Kartu Tanda Mahasiswa Online di STMIK Royal Kisaran," Jurteksi, vol. IV, no. 1, pp. 1320, 2017.

[5] A. N. Rachman, C. M. S. Ramdani, and E. N. F. Dewi, "Implementasi Aplikasi Toko Online Ganger Untuk Pendaur Ulang Sampah Berbasis Web di Tasikmalaya," J. Approriate
Technol. Community Serv., vol.

1, no. 1, pp. 6-13, 2020.

[6] Irianto, "Perancangan Sistem Informasi Pembuatan Kartu Tanda Mahasiswa Online di STMIK Royal Kisaran," Jurteksi, vol. 4, no. 1, pp. 1320, 2017.

[7] Sudarmin, "Analisis Perancangan Sistem Informasi Pendaftaran Siswa Baru pada SMK Taman Siswa Kisaran Menggunakan Web," Jurteksi, vol. V, no. 1, pp. 59-62, 2018.

[8] Sudarmin, "Analisis Perancangan Sistem Informasi Pendaftaran Siswa Baru pada SMK Taman Siswa Kisaran Menggunakan Web," Jurteksi, vol. 5, no. 1, pp. 59-62, 2018.

[9] O. D. Lestari and T. Christy, "ANALISIS

PERBANDINGAN

PENGIRIMAN BARANG

MENGGUNAKAN METODE VOGEL'S APPROXIMATION METHOD (VAM) DAN MODIFIED DISTRIBUTION (MODI)," Jurteksi, vol. 5, no. 1, pp. 51-58, 2018.

[10] R. Nofitri and N. Irawati, "ANALISIS DATA HASIL KEUNTUNGAN MENGGUNAKAN SOFTWARE RAPIDMINER," Jurteksi, vol. 5, no. 2, pp. 199204, 2019.

[11] R. A. Sukamto and M. Shalahuddin, Rekayasa Perangkat Lunak (Terstruktur dan Berorientasi Objek). Bandung: Informatika Bandung, 2016.

[12] Rizaldi, "Penerapan Waterfall Dalam Membangun Sistem 
DOI: https://doi.org/10.33330/jurteksi.v6i2.406

Available online at http://jurnal.stmikroyal.ac.id/index.php/jurteksi

Informasi Pengolahan data Pelaksanaan Konstruksi Pembangunan Jalan," Jurteksi, vol. 4, no. 1, pp. 71-78, 2017.

[13] D. R. Prehanto, "Rancang Bangun Sistem Informasi Inventarisasi Peralatan dan Bahan Laboratorium Berbasis Web di Jurusan Teknik Elektro Unesa," J. Manaj. Inform., vol. 4, no. 1, pp. 61-75, 2015.

[14] D. R. Prehanto, "Rancang Bangun Sistem Informasi Inventarisasi Peralatan dan
Bahan Laboratorium Berbasis Web di Jurusan Teknik Elektro UNESA," J. Manaj. Inform., vol. 04, no. 01, pp. 61-70, 2015.

[15] R. F. Lubis, "Perancangan Antarmuka Aplikasi Berbasis Web Menggunakan User Centered Design Dalam Pembelajaran Keragaman Budaya," Jurteksi, vol. IV, no. 1, pp. 1-6, 2017. 